\title{
И.О. Ткачев
}

\section{ОСВОБОЖДЕНИЕ ОТ УГОЛОВНОЙ ОТВЕТСТВЕННОСТИ В СВЯЗИ С ВОЗМЕЩЕНИЕМ УЩЕРБА (ст. 76.1 УК РФ)}

\begin{abstract}
Рассматриваются основания освобождения от уголовной ответственности, предусмотренные ст. 76.1 УК РФ в редакции Федерального закона от 27 декабря 2018 г. № 533-ФЗ. Автор приходит к выводу, что название статьи не соответствует ее содержанию. Возмещение ущерба выступает обязательным условием освобождения только в одном из трех самостоятельных оснований освобождения от уголовной ответственности, содержащихся в указанной статье. При этом в качестве основного условия освобождения в соответствии с ч. 2 ст. 76.1 УК РФ выступает уплата денежного возмещения в размере трехкратного эквивалента соответствующего признака. В связи с этим предлагается сформулировать одно общее основание освобождения от уголовной ответственности в связи с назначением денежной компенсации.
\end{abstract}

Ключевые слова: освобождение от уголовной ответственности, возмещение ущерба, судебный штраф, гуманизация уголовного законодательства.

Одной из отличительных тенденций современного этапа развития уголовного законодательства Российской Федерации является его гуманизация, которая касается в первую очередь ответственности за преступления в сфере экономической деятельности.

Важным инструментом такой гуманизации являются поощрительные нормы, устанавливающие основания и определяющие условия освобождения от уголовной ответственности. Отечественный законодатель последовательно расширяет возможность применения таких норм.

Еще в 2011 г. Уголовный кодекс РФ был дополнен ст. 76.1, устанавливающей возможность освобождения от уголовной ответственности по делам о преступлениях в сфере экономической деятельности [1]. Федеральным законом от 27 декабря 2018 г. № 533-Ф3 указанная статья изложена в новой редакции [2]. При этом изменение сформулированных в норме условий освобождения привело в итоге и к изменению наименования соответствующего правового института. В настоящее время данное основание освобождения именуется «освобождение в связи с возмещением ущерба».

Название статьи в действующей редакции явно не соответствует ее содержанию, на что уже обращалось внимание в специальной литературе [3, с. 25]. Положения ст. 76.1 УК РФ устанавливают три самостоятельных основания освобождения от уголовной ответственности, каждое из которых сформулировано в соответствующей части рассматриваемой статьи.

В чистом виде о возмещении ущерба говорится только в ч. 1 ст. 76.1 УК РФ, в соответствии с которой условием освобождения от уголовной ответственности за преступления, предусмотренные ст.ст. 198-199.1, 199.3, 199.4 УК РФ, является полное возмещение ущерба, причиненного соответствующим преступлением бюджетной системе Российской Федерации. В соответствии с п. 14 Постановления Пленума Верховного Суда РФ от 27 июня 2013 г. № 19 «О применении судами законодательства, регламентирующего основания и порядок освобождения от уголовной ответственности» под таким ущербом понимается сумма недоимки, пеней и штрафов в размере, определяемом в соответствии с законодательством Российской Федерации о налогах и сборах $[4$, с. 7]. При этом, как верно отмечает Е.В. Благов, возмещение ущерба выступает также условием освобождения в случаях, предусмотренных ст.ст. 75, $75,76.2$ УК РФ, в связи с чем не отражает специфику освобождения, предусмотренного анализируемой нормой [5, с. 119].

Следует отметить, что положения ч. 1 ст. 76.1 УК РФ по своему содержанию дублируют специальные основания освобождения от уголовной ответственности, содержащиеся в примечаниях к ст.ст. 198, 199, 199.1, 199.3 и 199.4 УК РФ [6, с. $170 ; 7$, с. 113$]$, в связи с чем представляются излишними. Данные предписания должны быть перенесены в примечания к соответствующим статьям Особенной части УК РФ [5, с. 124].

В ч. 2 ст. 76.1 УК РФ освобождение от уголовной ответственности связано с уплатой виновным лицом определенной денежной суммы. При этом размер такой суммы, исходя из содержания анализируемой нормы, может быть связан с размером:

- причиненного преступлением ущерба;

- дохода, полученного виновным в результате совершения преступления;

- убытков, которые удалось избежать виновному в результате совершения преступления;

- деяния, описанного в диспозиции уголовноправовой нормы.

Вместе с тем только в первом из указанных выше случаев условием освобождения выступает возмещение ущерба потерпевшему. Во всех остальных случаях в ч. 2 ст. 76.1 УК РФ, по сути, речь идет только о перечислении в федеральный бюджет определенного денежного возмещения. Более того, в таких случаях ущерб не является признаком объективной стороны состава совершенного преступления, а потерпевший отсутствует как в уголовно-правовом, так и в уголовнопроцессуальном смысле.

В отмеченных случаях сумма подлежащего уплате в федеральный бюджет денежного возмещения искусственно разрывается законодателем. Так, согласно соответствующей норме виновное лицо освобождается от уголовной ответственности «...если перечислило в фе- 
деральный бюджет доход, полученный в результате совериения преступления, и денежное возмещение в размере двукратной суммы дохода, полученного в результате совершения преступления...».

Очевидно, что в приведенном выше условии освобождения речь идет о перечислении в федеральный бюджет не именно тех денежных средств, которые были получены в результате совершения преступления, а их эквивалента. То есть, по сути, виновное лицо должно перечислить денежное возмещение в размере трехкратной суммы дохода, полученного в результате совершения преступления. Иными словами, если бы законодатель указал, что лицо освобождается от уголовной ответственности, если перечислило в федеральный бюджет денежное возмещение в размере трехкратной суммы дохода, полученного в результате совершения преступления, смысл уголовно-правового предписания остался бы неизменным.

Аналогичным образом построена анализируемая норма применительно к убыткам, которых удалось избежать в результате совершения преступления, и к размеру совершенного деяния. Здесь также речь идет об уплате трехкратного денежного эквивалента соответствующего юридически значимого признака.

Обращает на себя внимание также существенное расширение Федеральным законом от 27 декабря 2018 г. № 533-Ф3 перечня преступлений, за совершение которых лицо может быть освобождено от уголовной ответственности на основании ч. 2 ст. 76.1 УК РФ.

Первая попытка «реанимировать» указанную норму была предпринята путем принятия Федерального закона от 3 июля 2016 г. № 325-Ф3 [8], которым был существенно (с пятикратного до двукратного) снижен размер подлежащего уплате денежного возмещения. Однако к существенным изменениям в практике применения уголовного законодательства это не привело. Как следует из судебной статистики, опубликованной Судебным департаментом при Верховном Суде РФ, всего за 2018 г. по ст. 28.1 УПК РФ было прекращено 31 уголовное дело (при этом на налоговые преступления приходится 28 случаев). Для сравнения за тот же период по ст. 25.1 УПК РФ (в связи с назначением судебного штрафа) было прекращено 33329 уголовных дел [9].

Первоначально норма ч. 2 ст. 76.1 УК РФ могла быть применена в отношении 25 составов преступлений (включая основные и квалифицированные составы). После вступления в силу Федерального закона от 3 июля 2016 г. № 325-Ф3 - в отношении 33 составов. В настоящее время законодатель предусмотрел возможность освобождения по данному основанию за 45 составов преступлений, преимущественно относящихся к категориям небольшой или средней тяжести (к тяжким преступлениям относятся только преступления, предусмотренные ч. 6, 7 ст. 159, ст.ст. 196, 197, ч. 2 ст. 199.2 УК РФ).

Именно расширение перечня преступлений, в отношении которых возможно освобождение по основанию, предусмотренному ч. 2 ст. 76.1 УК РФ, привело к изменению наименования всей статьи. Если раньше сформулированные в ней положения касались только освобождения от уголовной ответственности за пре- ступления, предусмотренные гл. 22 УК РФ («Преступления в сфере экономической деятельности»), то в настоящее время в предусмотренный ч. 2 ст. 76.1 УК РФ перечень вошли также преступления гл. 19 УК РФ (ч. 1 ст. 146 и ч. 1 ст. 147 УК РФ) и гл. 21 УК РФ (ч. 5-7 ст. 159 , ч. 1 ст. 159.1 , ч. 1 ст. 159.2 , ч. 1 ст. 159.3 , ч. 1 ст. 159.5 , ч. 1 ст. 159.6 , ч. 1 ст. 160 , ч. 1 ст. 165 УК РФ).

При этом, согласно данным судебном статистики, в 2018 г. за преступления, которые были указаны в ч. 2 ст. 76.1 УК РФ в редакции Федерального закона от 3 июля 2016 г. № 325-Ф3, всего в РФ было осуждено 699 человек, а за преступления, которые были включены в перечень Федеральным законом от 27 декабря 2018 г. № 533-Ф3, - 5545 человек [10]. Таким образом, правоприменительный потенциал соответствующей нормы возрос на $793 \%$.

Следует особо отметить, что в предусмотренный ч. 2 ст. 76.1 УК РФ перечень преступных деяний были добавлены только те, которые преимущественно совершаются лицами, осуществляющими предпринимательскую деятельность в качестве органа управления юридического лица или индивидуального предпринимателя. Об этом же свидетельствует пояснительная записка к законопроекту, согласно которой его целями обозначены формирование благоприятного делового климата, создание гарантий защиты предпринимателей от необоснованного уголовного преследования [3, с. 25]. Законодатель сознательно не стал включать в перечень такие преступления, которые по характеру и степени общественной опасности схожи с содержащимися в нем преступлениями гл. 19 и 21 УК РФ, но совершаются лицами, имущественное положение которых в большинстве случаев не позволяет уплатить предусмотренную законом денежную компенсацию (например, кражу или мелкое хищение, совершенное лицом, подвергнутым административному наказанию).

В связи с вышеизложенным, по нашему мнению, отсутствуют принципиальные различия между основанием освобождения от уголовной ответственности, предусмотренным ч. 2 ст. 76.1 УК РФ, и таким основанием, как освобождение от уголовной ответственности в связи с назначением судебного штрафа (ст. 76.2 УК РФ).

И в том и в другом случае условием освобождения от уголовной ответственности являются:

1) совершение соответствующего преступления впервые;

2) отнесение законодателем совершенного преступления к категории небольшой или средней тяжести (кроме случаев освобождения от уголовной ответственности на основании ч. 2 ст. 76.1 УК РФ за преступления, предусмотренные ч. 6 и 7 ст. 159, ст.ст. 196, 197, ч. 2 ст. 199.2 УК РФ);

3) возмещение ущерба (заглаживание вреда), причиненного совершенным преступлением;

4) уплата денежного возмещения (в ст. 76.2 УК РФ судебного штрафа) в бюджет Российской Федерации.

Как верно отмечает А.М. Каримов, именно для двух указанных оснований освобождения от уголовной ответственности характерно карательное воздействие на виновного [11, с. 89]. В связи с этим денежное возмещение (как и судебный штраф) может рассматриваться 
как мера уголовно-правового характера, хотя в литературе встречается и противоположный подход [12, с. 7]. При этом положения и ч. 2 ст. 76.1, и ст. 76.2 УК РФ могут применяться в случаях, когда диспозиция соответствующей статьи Уголовного кодекса РФ не предусматривает причинение ущерба или иного вреда в качестве обязательного признака объективной стороны преступления (преступления с формальным составом) [13].

В свою очередь, различия между институтами судебного штрафа и денежного возмещения, предусмотренного ч. 2 ст. 76.1 УК РФ, заключаются в следующем.

1. Основание освобождения от уголовной ответственности с назначением судебного штрафа является диспозитивным, тогда как при соблюдении условий освобождения, предусмотренных ч. 2 ст. 76.1 УК РФ, лицо императивно подлежит освобождению от уголовной ответственности судом или лицом, в чьем производстве находится соответствующее уголовное дело.

2. Судебный штраф уплачивается после освобождения лица от уголовной ответственности в установлен- ный судебным актом срок, а денежное возмещение - до момента удаления суда в совещательную комнату для постановления приговора $[4$, с. 7]. Собственно, освобождение от уголовной ответственности на основании ст. 76.2 УК РФ - единственное из предусмотренных гл. 11 УК РФ, которое сформулировано по модели условного, т.е. поставлено в зависимость от последующего поведения виновного. Уплатой судебного штрафа подлежащее освобождению лицо должно доказать свое исправление без применения к нему каких-либо иных мер уголовно-правового характера. Таким образом, указанная норма имеет ярко выраженный стимулирующий потенциал.

При этом обобщение статистических данных показывает, что расчет законодателя оказался оправданным. Доля добровольно уплаченных судебных штрафов, назначаемых в качестве иной меры уголовно-правового характера, значительно выше аналогичного показателя в отношении штрафов, назначаемых в качестве основного или дополнительного наказания (таблица) [14].

Соотношение добровольно уплаченных судебных штрафов, назначаемых в качестве иной меры уголовно-правового характера, и штрафов, назначаемых в качестве основного или дополнительного наказания

\begin{tabular}{|c|c|c|c|c|c|c|c|c|}
\hline \multirow[t]{2}{*}{ Период } & \multicolumn{2}{|c|}{ 1-е полугодие 2017 г. } & \multicolumn{2}{|c|}{ 2-е полугодие 2017 г. } & \multicolumn{2}{|c|}{ 1-е полугодие 2018 г. } & \multicolumn{2}{|c|}{ 2-е полугодие 2018 г. } \\
\hline & $\begin{array}{l}\text { Штраф как } \\
\text { иная мера }\end{array}$ & $\begin{array}{l}\text { Штраф как } \\
\text { наказание }\end{array}$ & $\begin{array}{c}\text { Штраф как } \\
\text { иная мера }\end{array}$ & $\begin{array}{l}\text { Штраф как } \\
\text { наказание }\end{array}$ & $\begin{array}{l}\text { Штраф как } \\
\text { иная мера }\end{array}$ & $\begin{array}{l}\text { Штраф как } \\
\text { наказание }\end{array}$ & $\begin{array}{l}\text { Штраф как } \\
\text { иная мера }\end{array}$ & $\begin{array}{l}\text { Штраф как } \\
\text { наказание }\end{array}$ \\
\hline $\begin{array}{l}\text { Назначено, } \\
\text { млн. руб. }\end{array}$ & 108,4 & 4222,89 & 171 & 4927,07 & 226,1 & 5204,96 & 294,1 & 6321,36 \\
\hline $\begin{array}{l}\text { Добровольно уплачено, } \\
\text { млн. руб. }\end{array}$ & 39,9 & 317,98 & 67,3 & 415,72 & 91 & 347,63 & 125,51 & 772,56 \\
\hline $\begin{array}{l}\text { Доля добровольно упла- } \\
\text { ченных средств, \% }\end{array}$ & 36,8 & 7,53 & 39,35 & 8,44 & 40,24 & 6,68 & 42,67 & 12,22 \\
\hline
\end{tabular}

Представляется, что отмеченный выше стимулирующий потенциал нормы, предусмотренной ст. 76.2 УК РФ, можно распространить и на случаи освобождения от уголовной ответственности, которые в настоящее время предусмотрены ч. 2 ст. 76.1 УК РФ.

3. Размер судебного штрафа зависит от того, предусмотрено ли санкцией статьи Особенной части УК РФ наказание в виде штрафа. В соответствии с п. 8 Обзора судебной практики освобождения от уголовной ответственности с назначением судебного штрафа (ст. 76.2 УК РФ) (утв. Президиумом Верховного Суда РФ 10 июля 2019 г.) [13], размер судебного штрафа определяется судом с учетом тяжести совершенного преступления и имущественного положения лица, освобождаемого от уголовной ответственности, и его семьи, а также с учетом возможности получения указанным лицом заработной платы или иного дохода.

В то же время применительно к ч. 2 ст. 76.1 УК РФ размер денежного возмещения определяется с учетом причиненного преступлением ущерба, дохода, полученного виновным в результате совершения преступления, убытков, которых удалось избежать виновному в результате совершения преступления, либо размера деяния, описанного в диспозиции уголовно-правовой нормы, что, по нашему мнению, больше соответствует принципу справедливости, согласно которому наказание и иные меры уголовно-правового характера, применяемые к лицу, совершившему преступление, должны быть справедливыми, т.е. соответствовать характеру и степени общественной опасности преступления, обстоятельствам его совершения и личности виновного (ч. 1 ст. 6 УК РФ).
4. Применительно к ч. 2 ст. 76.1 УК РФ лицо признается впервые совершившим преступление, если оно не имеет неснятую или непогашенную судимость за преступление, предусмотренное той же статьей, от ответственности по которой оно освобождается. В то же время для целей применения ст. 76.2 УК РФ лицо считается совершившим преступление впервые, если не имеет неснятую или непогашенную судимость за любое из ранее совершенных преступлений $[4$, с. 6], что соответствует общему, а не специальному характеру освобождения от уголовной ответственности.

При этом столь значительное расширение перечня преступлений, за которые лицо может быть освобождено от уголовной ответственности на основании положений ч. 2 ст. 76.1 УК РФ, заставляет задуматься о возможности отнесения соответствующего основания к числу специальных. На самом деле, по нашему мнению, отсутствуют достаточные социальные основания для освобождения от уголовной ответственности лица, совершившего, например, мошенничество в сфере кредитования, если такое лицо имеет неснятую и непогашенную судимость за общий состав мошенничества. Положения, сужающие объем категории «лицо, впервые совершившее преступление» до категории «лицо, впервые совершившее преступление, от уголовной ответственности за которое лицо освобождается», должны содержаться только в примечаниях к статьям Особенной части УК РФ, устанавливающим специальные основания освобождения от уголовной ответственности.

Наконец, в ч. 3 ст. 76.1 УК РФ сформулировано еще одно самостоятельное основание освобождения от уго- 
ловной ответственности. При этом в данном случае речь о каком-либо возмещении ущерба вообще не ведется. Согласно указанной норме, условием освобождения является подача самим виновным или в его отношении специальной декларации в соответствии с Федеральным законом «О добровольном декларировании физическими лицами активов и счетов (вкладов) в банках и о внесении изменений в отдельные законодательные акты Российской Федерации». При этом в названной норме специально указывается, что в случае подачи такой декларации не применяются положения ч. 1 и 2 ст. 76.1 УК РФ в части возмещения ущерба, перечисления в федеральный бюджет денежного возмещения и полученного дохода. То есть сам законодатель не связывает освобождение от уголовной ответственности с каким-либо возмещением ущерба.

Более того, возмещение ущерба бюджетной системе не указано в качестве целей правового регулирования в ст. 1 Федерального закона от 8 июня 2015 г. № 140-Ф3 «О добровольном декларировании физическими лицами активов и счетов (вкладов) в банках и о внесении изменений в отдельные законодательные акты Российской Федерации». Как следует из содержания названной статьи, соответствующий закон направлен на создание правового механизма добровольного декларирования активов и счетов (вкладов) в банках, обеспечение правовых гарантий сохранности капитала и имущества физических лиц, защиту их имущественных интересов, в том числе за пределами Российской Федерации, снижение рисков, связанных с возможными ограничениями использования российских капиталов, которые находятся в иностранных государствах, а также с переходом Российской Федерации к автоматическому обмену налоговой информацией с иностранными государствами [15].

Как отмечено в пояснительной записке к проекту указанного выше федерального закона, он предусматривает решение следующих задач:

1) снижение рисков, связанных с возможными ограничениями использования российских капиталов, которые находятся в иностранных государствах, а также с переходом Российской Федерации к автоматическому обмену налоговой информацией с иностранными государствами;

2) создание в законодательстве Российской Федерации правовых оснований для передачи имущества, принадлежащего на праве собственности лицам, которые владеют, пользуются и распоряжаются этим имуществом в чужом интересе, в пользу фактических владельцев этого имущества без возникновения обязанности по уплате налогов в связи с такой передачей;

3) создание стимулов для добросовестного исполнения физическими лицами обязанностей, установленных законодательством о налогах и сборах, законодательством о валютном регулировании и валютном контроле, таможенным законодательством;

4) определение гарантий правовой защиты имущественных интересов физических лиц, участвующих в добровольном декларировании имущества и счетов (вкладов) в банках, конфиденциальности полученной информации, освобождения таких физических лиц от уголовной, административной ответственности и ответственности за налоговые правонарушения [16].

Таким образом, возмещение ущерба, причиненного бюджетной системе Российской Федерации, не является ни условием освобождения от уголовной ответственности, сформулированным в ч. 3 ст. 76.1 УК РФ, ни целью или задачей института добровольного декларирования активов и счетов (вкладов) в банках.

В связи с этим следует признать, что в ч. 3 ст. 76.1 УК РФ сформулировано самостоятельное основание освобождения от уголовной ответственности, условием которого не является возмещение ущерба, причиненного бюджетной системе РФ.

Изложенное позволяет сформулировать следующие выводы и предложения:

1. Название ст. 76.1 УК РФ не соответствует ее действительному содержанию, поскольку возмещение ущерба выступает в качестве обязательного условия освобождения от уголовной ответственности только в ч. 1 ст. 76.1 УК РФ.

2. Положения ч. 1 ст. 76.1 УК РФ дублируют специальные основания освобождения от уголовной ответственности, содержащиеся в примечаниях к статьям Особенной части УК РФ, в связи с чем соответствующая норма подлежит исключению из уголовного закона.

3. Норма ч. 2 ст. 76.1 УК РФ с учетом значительно расширенного перечня преступлений, при совершении которых лицо может быть освобождено от уголовной ответственности, должна рассматриваться в качестве общего, а не специального основания освобождения от уголовной ответственности.

4. С учетом наличия общих черт у оснований освобождения от уголовной ответственности, предусмотренных ч. 2 ст. 76.1 УК РФ и ст. 76.2 УК РФ, законодателю стоит задуматься об унификации соответствующих правовых предписаний и сформулировать одно общее основание освобождения от уголовной ответственности в связи с назначением уголовно-правового возмещения. В качестве условий освобождения по указанному основанию должны выступать:

1) совершение преступления впервые;

2) отнесение преступления к категории небольшой или средней тяжести;

3) возмещение ущерба или заглаживание причиненного преступлением вреда иным образом;

4) уплата в установленный судом срок денежного возмещения в бюджет Российской Федерации в размеpe, который с учетом положений ст. 6 УК РФ зависит от размера причиненного преступлением ущерба, дохода, извлеченного в результате совершения преступления, убытков, которые удалось избежать в результате совершения преступления, размера (стоимости) предмета преступления или размера преступного деяния.

\section{ЛИТЕРАТУРА}

1. Собрание законодательства РФ. 2011. 12 дек. № 50. Ст. 7362.

2. Собрание законодательства РФ. 2018. 31 дек. № 53 (ч. І). Ст. 8459. 
3. Власенко В.В. «Реинкарнация» ст. 76.1 УК РФ и другие новеллы института освобождения от уголовной ответственности: законодательные погрешности и перспективы применения // Российская юстиция. 2019. № 8. С. $25-27$.

4. Бюллетень Верховного Суда РФ. 2013. № 8 .

5. Благов E.B. Освобождение от уголовной ответственности в связи с возмещением ущерба // Актуальные проблемы российского права. 2019. № 8. С. 118-127.

6. Качество уголовного закона: проблемы Общей части / отв. ред. А.И. Рарог. М. : Проспект, 2016. 288 с.

7. Макарова О.В. освобождение от уголовной ответственности по делам о преступлениях в сфере экономической деятельности // Журнал российского права. 2015. № 1. С. 111-118.

8. Собрание законодательства РФ. 2016. 4 июля. № 27 (ч. ІІ). Ст. 4258.

9. Отчет об особенностях рассмотрения уголовных дел, применения реальных видов наказания и оснований прекращения уголовных дел : на основании формы № 10.2. URL: http://www.cdep.ru/index.php?id=79\&item=4894 (дата обращения: 03.11.2019).

10. Отчет о числе осужденных по всем составам преступлений УК РФ : на основании формы № 10-a. URL: http://www.cdep.ru/index.php?id=79\&item=4894 (дата обращения: 03.11.2019).

11. Каримов А.М. Заглаживание вреда, причиненного совершением преступления, как основание освобождения от уголовной ответственности с назначением судебного штрафа // Алтайский юридический вестник. 2019. № 3. С. 87-92.

12. Валеев М.Т. Денежное возмещение, предусмотренное ч. 2 ст. 76.1 УК РФ, как элемент «квазиуголовного права»// Уголовная юстиция. 2016. № 2. С. 5-10.

13. Обзор судебной практики освобождения от уголовной ответственности с назначением судебного штрафа (статья 76.2 УК РФ) : (утв. Президиумом Верховного Суда РФ 10.07.2019). URL: http://www.supcourt.ru/documents/thematics/28088/ (дата обращения: 03.11.2019).

14. Отчет судов общей юрисдикции о суммах ущерба от преступлений, суммах материальных взысканий в доход государства, количестве вынесенных постановлений об оплате процессуальных издержек за счет средств федерального бюджета и назначении экспертиз : на основании формы № 4. URL: http://www.cdep.ru/index.php?id=79 (дата обращения: 01.11.2019).

15. Собрание законодательства РФ. 2015. 15 июня. № 24. Ст. 3367.

16. Пояснительная записка к проекту федерального закона «О добровольном декларировании физическими лицами имущества и счетов (вкладов) в банках» // Комитет Государственной думы РФ по бюджету и налогам. URL: https://sozd.duma.gov.ru/ bill/754388-6 (дата обращения: 02.11.2019).

\section{Exemption from Criminal Liability in Connection with Restitution for Damage (Article 76.1 of the Criminal Code of the Russian} Federation)

Ugolovnaya yustitsiya - Russian Journal of Criminal Law, 2019, no. 14, pp. 30-35. DOI 10.17223/23088451/14/7

Igor O. Tkachev, Ural State Law University (Yekaterinburg, Russian Federation). E-mail: tkachyov@mail.ru

Keywords: exemption from criminal liability, restitution, judicial fine, humanization of criminal law.

As far as Part 2 of Article 76.1 and Article 76.2 of the Criminal Code of the Russian Federation provide for similarities in the grounds for exemption from criminal liability, the legislator is to think about unifying the relevant legal requirements to state one general basis for exemption from criminal liability in connection with the restitution. The conditions for exemption on the indicated grounds should include: committing an offense for the first time; classifying a crime as minor or moderate; compensation for damage or a different type expiation; paying within the period established by the court of monetary compensation to the budget of the Russian Federation in the amount which, under provisions of Article 6 of the Criminal Code of the Russian Federation, depends on the extent of the damage caused by the crime, income derived from the commission of the crime, losses avoided as a result of the crime, the extent (cost) of the subject of the crime or the extent of the criminal act.

\section{References}

1. The Russian Federation. (2011) Sobranie zakonodatel'stva RF [The Legislative Bulletin of the Russian Federation]. 12th December 2011. Art. 7362.

2. The Russian Federation. (2018) Sobranie zakonodatel'stva RF [The Legislative Bulletin of the Russian Federation]. 31st December 2018. Art. 8459.

3. Vlasenko, V.V. (2019) "Reincarnation" of Article 76.1 of the Criminal Code and other novelties of the institute of exemption from criminal liability: legislative errors and prospects of application. Rossiyskaya yustitsiya - Russian Justitia. 8. pp. 25-27. (In Russian).

4. Byulleten' Verkhovnogo Suda RF. (2013) 8.

5. Blagov, E.V. (2019) Relief from criminal responsibility for damages. Aktual'nye problemy rossiyskogo prava - Actual Problems of Russian Law. 8. pp. 118-127. (In Russian). DOI: 10.17803/1994-1471.2019.105.8.118-127

6. Rarog, A.I. (ed.) (2016) Kachestvo ugolovnogo zakona: problemy Obshchey chasti [The quality of the criminal law: problems of the General Part]. Moscow: Prospekt.

7. Makarova, O.V. (2015) Exemption from Criminal Responsibility in Cases over Crimes in the Field of Economic Activity. Zhurnal rossiyskogo prava - Journal of Russian Law. 1. pp. 111-118. (In Russian).

8. The Russian Federation. (2016) Sobranie zakonodatel'stva RF [The Legislative Bulletin of the Russian Federation]. 4th July. Art. 4258.

9. The Judicial Department of the Supreme Court of the Russian Federation. (n.d.) Otchet ob osobennostyakh rassmotreniya ugolovnykh del, primeneniya real'nykh vidov nakazaniya i osnovaniy prekrashcheniya ugolovnykh del [Report on the peculiarities of considering criminal cases, applying real types of punishment and the grounds for terminating criminal cases]. [Online] Available form: http://www.cdep.ru/index.php?id=79\&item=4894 (Accessed: 3rd November 2019).

10. The Judicial Department of the Supreme Court of the Russian Federation. (n.d.) Otchet o chisle osuzhdennykh po vsem sostavam prestupleniy UK RF [Report on the number of convicts for all offenses of the Criminal Code of the Russian Federation]. [Online] Available form: http://www.cdep.ru/index.php?id=79\&item=4894 (Accessed: 3rd November 2019).

11. Karimov, A.M. (2019) Compensation for harm caused by commission of a crime as the basis for exemption from criminal liability with the appointment of a judicial fine. Altayskiy yuridicheskiy vestnik-Altai Law Journal. 3. pp. 87-92. (In Russian). 
12. Valeev, M.T. (2016) Monetary reimbursement under Part 2 of Art. 76.1 of the Criminal Code of the Russian Federation as an element of “quasi-criminal law". Ugolovnaya yustitsiya - Russian Journal of Criminal Law. 2. pp. 5-10. DOI: 10.17223/23088451/8/1

13. The Supreme Court of the Russian Federation. (2019) Punkt 1 Obzora sudebnoy praktiki osvobozhdeniya ot ugolovnoy otvetstvennosti s naznacheniem sudebnogo shtrafa (stat'ya 76.2 UK RF) (utv. Prezidiumom Verkhovnogo Suda RF 10.07.2019) [Clause 1 of the Review of the judicial practice of exemption from criminal liability with a fine (Article 76.2 of the Criminal Code of the Russian Federation) (approved by the Presidium of the Supreme Court of the Russian Federation on July 10, 2019)]. [Online] Available form: http://www.supcourt.ru/documents/thematics/28088/ (Accessed: 3rd November 2019).

14. The Judicial Department of the Supreme Court of the Russian Federation. (n.d.) Otchet sudov obshchey yurisdiktsii o summakh ushcherba ot prestupleniy, summakh material'nykh vzyskaniy $v$ dokhod gosudarstva, kolichestve vynesennykh postanovleniy ob oplate protsessual'nykh izderzhek za schet sredstv federal'nogo byudzheta i naznachenii ekspertiz [Report of courts of general jurisdiction on the amount of damage from crimes, the amount of pecuniary punishment in state revenue, the number of decisions on the payment of procedural costs from the federal budget and the appointment of examinations]. [Online] Available form: http://www.cdep.ru/index.php?id=79 (Accessed: 1st November 2019).

15. The Russian Federation. (2011) Sobranie zakonodatel'stva RF [The Legislative Bulletin of the Russian Federation]. 15th June. Art. 3367.

16. The State Duma Committee on Budget and Taxes. (n.d.) Poyasnitel'naya zapiska k proektu federal'nogo zakona "O dobrovol'nom deklarirovanii fizicheskimi litsami imushchestva i schetov (vkladov) v bankakh" [Explanatory note to the draft federal law "On the voluntary declaration by individuals of property and accounts (deposits) in banks"]. [Online] Available form: https://sozd.duma.gov.ru/bill/754388-6 (Accessed: 2nd November 2019). 